\title{
Notes on the vocalizations of Bushtit (Psaltriparus minimus)
}

Peter Boesman

In the following we briefly analyze and compare voice of the different races of Bushtit (Psaltriparus minimus). We also try to quantify the extent of any vocal differences using the criteria proposed by Tobias et al. (2010), as a support for taxonomic review. We have made use of sound recordings available on-line from Xeno Canto (XC).

All races have a variety of single call notes, out of which the trilled high-pitched call seems to be the most complex one. We will compare here this particular vocalization, as there is no doubt it can be considered homologous among the different races.

"Pacific group" (nominate, and also saturatus, melanurus, californicus and grindae) of Pacific coastal regions

S California

Vancouver
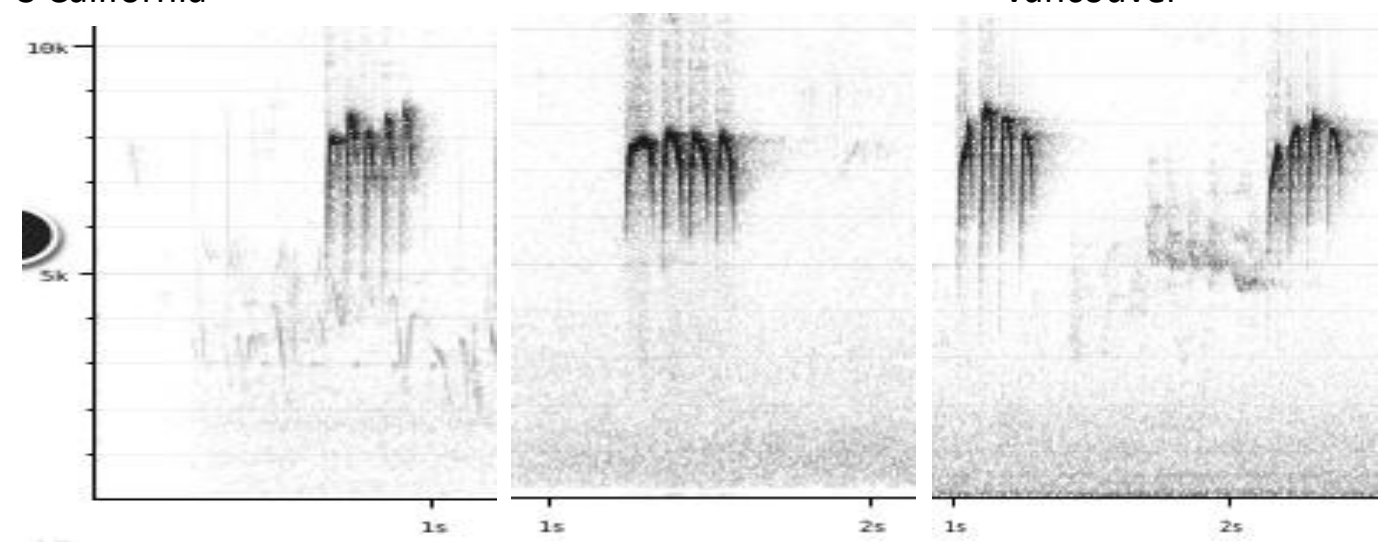

Baja California (Mexico) (grindae)

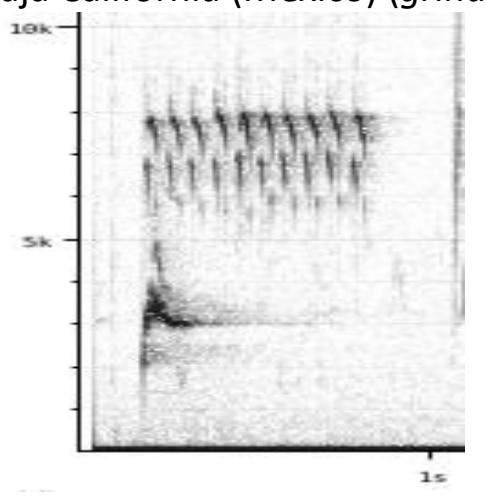



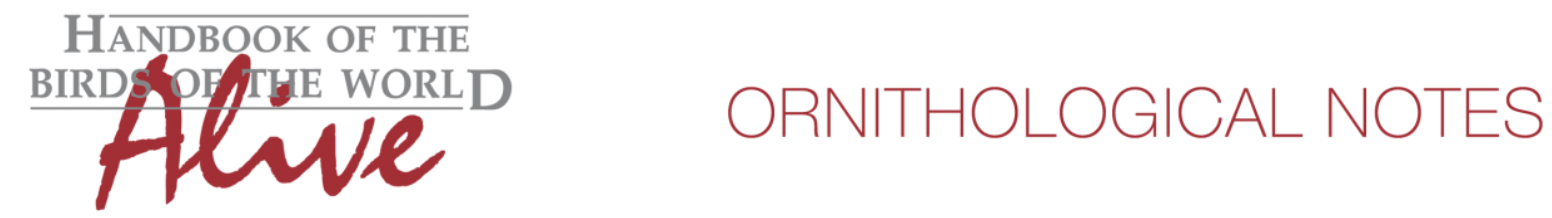

"Interior group" (plumbeus) in interior Colorado

S Texas

S Arizona

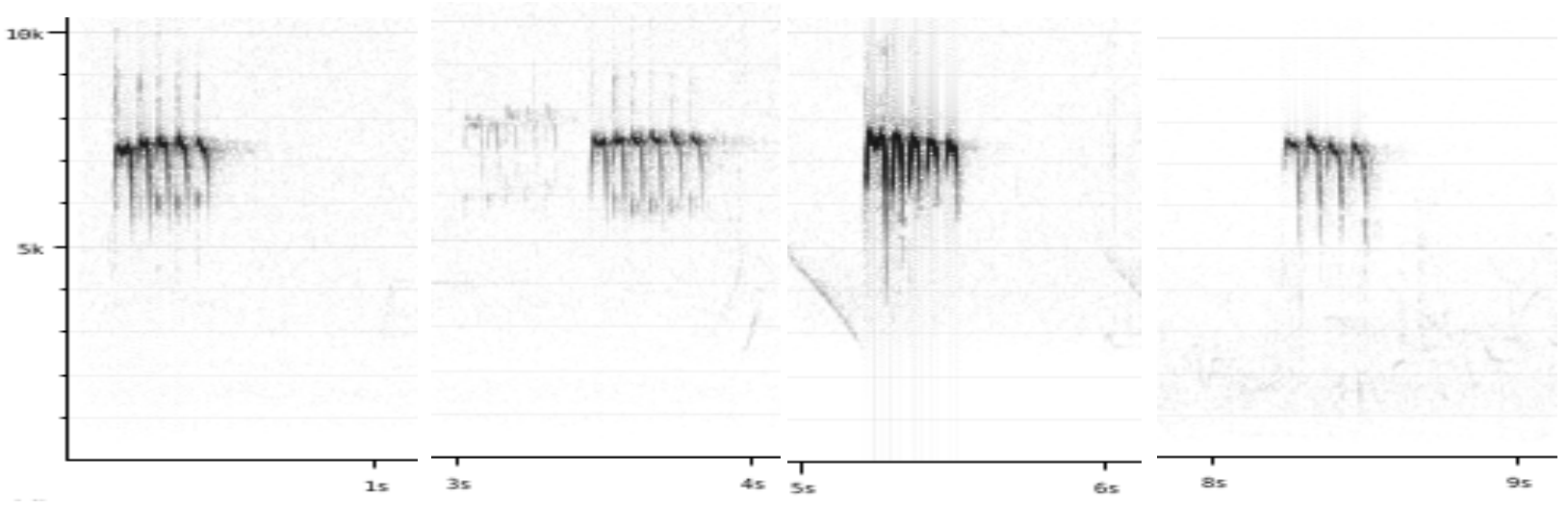

"Southern group" (melanotis, and also dimorphicus, iulus and personatus) in S of range (Mexico) Oaxaca Mexico DF NE Mexico
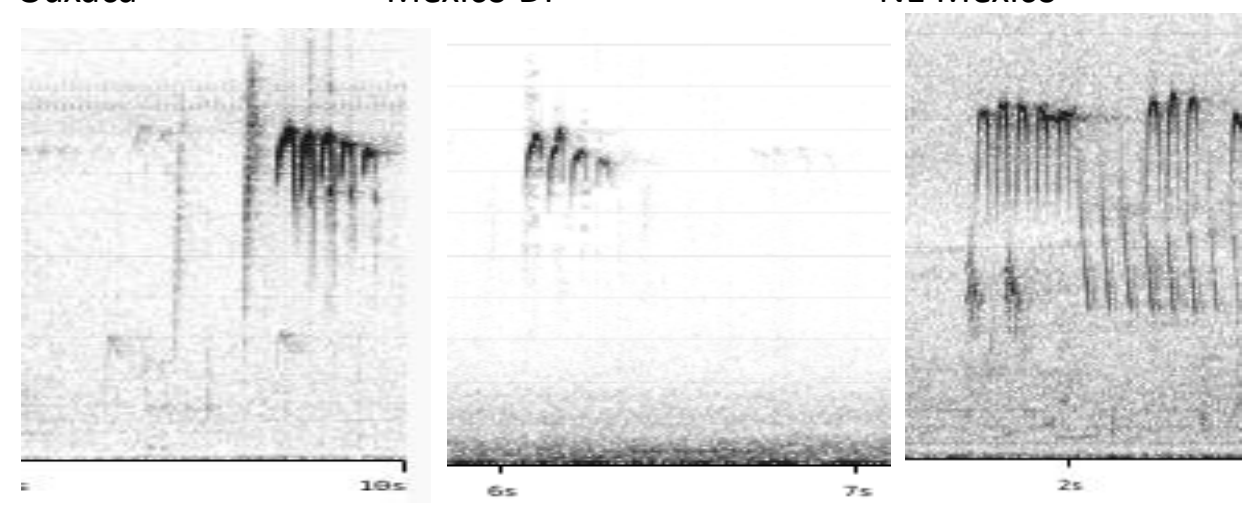

There seems to be little vocal difference between the three groups (with the exception of the single recording of grindae which is rather atypical). Note shapes show subtle differences, but no clear pattern.

The only apparent difference is that the Pacific group reaches higher max. frequencies, but also occasionally the lowest, while the interior group reaches typically low max. frequencies and the southern group typically only high max. frequencies:

Pacific $(n=11)$ :

Interior $(n=9)$ :

South $(n=4)$ :
$8.12 \mathrm{kHz}$
$0.8 \mathrm{kHz}$

$0.16 \mathrm{kHz}$

$0.12 \mathrm{kHz}$

Effect Size calculation:

Pacific vs Interior: 0.4 -> score 1

Pacific vs South: 0.68 -> score 1

Interior vs South: 4.4 -> score 2

When more recordings of the southern group become available, there may however be an increase in spread. Present scores should thus be considered maximum values. 
Also, more recordings of the trilled call of grindae are desirable, to find out whether there is indeed a consistent difference in note shape.

This note was finalized on 5th March 2016, using sound recordings available on-line at that moment. We would like to thank in particular the many sound recordists who placed their recordings for this species on XC.

\section{References}

Tobias, J.A., Seddon, N., Spottiswoode, C.N., Pilgrim, J.D., Fishpool, L.D.C. \& Collar, N.J. (2010). Quantitative criteria for species delimitation. Ibis 152(4): 724-746.

\section{Recommended citation}

Boesman, P. (2016). Notes on the vocalizations of Bushtit (Psaltriparus minimus). HBW Alive Ornithological Note 258. In: Handbook of the Birds of the World Alive. Lynx Edicions, Barcelona. (retrieved from http://www.hbw.com/node/1251557 on 4 October 2016). 